\title{
ALIMENTAÇÃO DURANTE O CONFINAMENTO DA COVID-19: UM PROCESSO DE DECISÃO PARTICIPATIVA USANDO OTIMIZAÇÃO LINEAR ${ }^{1}$
}

\author{
Leila Abuabara ${ }^{\text {ab }^{*}}$ \\ ${ }^{a}$ Universidade Federal de São Paulo - UNIFESP, São José dos Campos-SP, Brasil \\ 'Instituto Tecnológico Aeronáutico - ITA, São José dos Campos-SP, Brasil
}

Recebido 13/07/2020, aceito 23/12/2020

\begin{abstract}
RESUMO
Durante o período de distanciamento social adotado pelo Governo do Estado de São Paulo em março de 2020 para controle da pandemia de Covid-19, uma das preocupações foi o suprimento de alimentos. Percebido que não haveria escassez, o foco passou a ser a adoção de uma alimentação de qualidade. As incertezas da duração da quarentena, a necessidade de se fazer todas as refeições em casa, juntos, e a recomendação de se minimizar saídas motivaram a realização deste trabalho. Mesmo em família, tem-se necessidades e preferências individuais a serem consideradas dentro do processo decisório. Através da combinação de um método participativo para escolhas individuais e otimização linear, propusemos uma estrutura metodológica para definição de um cardápio semanal que atendesse da melhor forma possível as expectativas de todos. Adicionalmente, o problema incluiu uma ação solidária: as compras para uma vizinha do grupo de risco, cujo distanciamento social era ainda mais rigoroso.
\end{abstract}

Palavras-chave: Alimentação, Otimização linear, AHP, Tomada de decisão.

\begin{abstract}
During the social distancing period adopted by the Government of the São Paulo State in March 2020, aiming to control the Covid-19 pandemic, one of the concerns was food supply. Once realized that there would be no shortage, the focus became the adoption of a quality feeding. Uncertainties about the quarantine duration, the need to have all meals at home, in family, and the recommendation to minimize outings motivated this work. Even within the family, there are individual needs and preferences to be considered in the decision-making process. By combining a participatory method for individual choices and linear optimization, we proposed a methodological framework to define a weekly menu that best meets everyone's expectations. Additionally, the problem included a solidarity action: the risk group neighbor shopping list, whose social distancing was even stricter.
\end{abstract}

Keywords: Feeding, Linear optimization, AHP, Decision making.

*Autor para correspondência. E-mail: leila.abuabara@unifesp.br.

DOI: 10.4322/PODes.2021.008 


\section{Introdução}

O anúncio de uma quarentena pelo Governo do Estado de São Paulo no fím de março de 2020 forçou milhares de famílias a interromperem repentinamente suas atividades e ficarem em casa. De um dia para o outro, escritórios, escolas, parques, academias, centros comerciais foram simplesmente fechados. E uma ordem de permanência em casa foi enfaticamente recomendada. O principal motivo foi manter o distanciamento social a fim de se tentar reduzir a transmissão do COVID-19, doença causada pelo corona-vírus SARS-CoV-2 (Ministério da Saúde, 2020a) e, desta forma, não sobrecarregar o sistema de saúde, público e privado, já que as estadias em unidades de terapias intensivas, quando necessárias, costumavam ser longas. Naquele momento, já sabíamos o quão agressivo e contagioso o vírus poderia ser apenas acompanhando as notícias da China (origem da pandemia), países europeus como Itália, Espanha e França, e, Estados Unidos, que estavam num estágio à frente em relação ao Brasil.

A pandemia fez surgir numerosas questões, das quais muitas tocaram cada um de nós de alguma forma. Entre elas, temos novas configurações de ensinar as crianças, de trabalhar, de se exercitar e manter a saúde, de sociabilizar e manter contato, a maneira como vivemos e comemos em casa e assim por diante. Em uma pesquisa na qual o Ministério da Saúde (2020b) indagou como a população estava enfrentando a pandemia, alguns comportamentos de risco foram identificados. Além de distúrbios de sono, problemas de saúde mental e no estado de ânimo, aumento do consumo de bebidas alcóolicas e fumo, destaco aqui a desordem alimentar. Esse estudo revelou que cerca de $38,7 \%$ dos entrevistados relataram aumento ou falta de apetite. Num outro, feito pela Unicamp (Coll, 2020) foi evidenciada uma redução no consumo de alimentos saudáveis acompanhada da queda da prática de atividades físicas. Esses estudos não se limitam ao âmbito nacional. Foi constatado que o estresse mental causado pela pandemia associado à indisponibilidade de alimentos frescos como frutas e hortaliças e mudanças nas condições financeiras afetaram negativamente o comportamento alimentar da população de classe média na Índia (Mehta, 2020). Entre italianos que participaram de uma pesquisa sobre hábitos alimentares e estilo de vida, houve uma percepção de ganho de peso por quase metade dos entrevistados, porém uma atenção maior foi dada ao consumo de produtos frescos cultivados nas proximidades (Di Renzo et al., 2020).

A partir de um outro panorama, a alimentação também foi uma forma das famílias se aproximarem e fortalecerem as relações interpessoais e laços familiares, seja decidindo-se o que se vai comer ou preparando as refeições juntos (Tuchlinski, 2020; Dou et al., 2020). Para crianças e leigos no assunto, foi também uma oportunidade de se familiarizar com a cozinha, com a linguagem culinária, aprender a ter autonomia e promover na prática uma alimentação saudável.

Neste contexto, uma nova dinâmica teve que ser estabelecida. Acredita-se, também por ser um instinto humano, que a primeira preocupação das famílias foi garantir o suprimento de alimentos (Jovančević e Milićević, 2020), o que logo se provou desnecessária (Dou et al., 2020), uma vez que não haveria escassez de nenhum produto alimentício. Por outro lado, independentemente do período de quarentena, ainda indefinido, pode-se assumir que, uma vez confinados em casa e privados das atividades diárias, o gasto calórico já não seria o habitual. No entanto, manter uma boa saúde, física e emocional, deve merecer uma atenção central. $\mathrm{O}$ principal interesse nesta pesquisa é explorar o modo de se alimentar bem, de forma consciente e com alegria durante esse período tão inesperado e delicado. A alimentação desempenha um papel central na promoção à saúde, especialmente em tempos de pandemia, em que é fundamental fortalecer a imunidade através também do controle de peso, cada vez mais posto em risco com as condições de isolamento social e confinamento (Jackson-Morris et al., 2020).

Um padrão alimentar é uma configuração particular do espaço social alimentar (Poulain e Proença, 2003, p.246) e durante todo o período de confinamento, essa conexão bioantropológica ficaria restrita à unidade familiar (ou às pessoas que moram dentro de um mesmo ambiente, independentemente do tamanho, da composição ou dos laços existentes entre elas). Como a alimentação carrega consigo aspectos biológicos, psicológicos, sociais (Poulain e Proença, 2003), culturais e econômicos (Maciel e Castro, 2013; Assis e Nahas, 1999), não temos 
outra opção senão a de incluir todos os membros dessa mesma unidade familiar na participação das decisões de alimentação. Tais decisões englobam preferências individuais que incluem aspectos subjetivos, tais como sensação de recompensa, conforto, que aumentam o bom humor, e devem também respeitar certos aspectos muito objetivos, como consumo calórico, disponibilidade nos mercados, preços de venda, práticas (e.g. vegetarianismo, veganismo), crenças (e.g. ligadas à religião) ou restrições alimentares (e.g. alergias, doença celíaca), por exemplo. Num estudo sobre comportamento do consumidor durante a pandemia realizado na Espanha (Laguna et al., 2020), foi revelado que a saúde foi a principal motivação para priorizar a compra de certos produtos no supermercado. Esse conceito foi dividido em saúde física (controle de peso) e saúde mental (humor). Deliberadamente uma perspectiva objetiva e subjetiva, respectivamente.

O objetivo desta pesquisa é explorar uma maneira ótima de planejar uma dieta adequada e consciente considerando as condições de confinamento, que são particulares a cada unidade familiar, mas que incluem trazer o 'mundo para dentro de casa'. E aqui damos alguns exemplos como a instalação de um estúdio de gravação ou de uma bancada para trabalhos manuais, a designação de um espaço de trabalho para cada profissão e profissional, um espaço de estudo e aprendizado para cada aluno, uma área de recreação para as crianças ou o que quer que a rotina de cada família exija. E de repente a organização e o gerenciamento de todas essas atividades, compartilhadas num mesmo espaço físico ficaram sob a responsabilidade de cada unidade familiar, uma verdadeira sobrecarga de tarefas que precisam ser pensadas com atenção. $O$ planejamento alimentar consciente é apenas uma dessas tarefas, já que o apoio terceirizado da alimentação estaria limitado (restaurantes e cantinas cessando suas atividades, além de restrições econômicas). A falta de planejamento alimentar abre espaço para refeições rápidas e fáceis, geralmente ultra processadas, com alto teor de gordura, açúcares e calorias vazias. E aqui colocamos a principal questão de pesquisa que será focada neste artigo: como uma unidade familiar pode gerenciar com sucesso o planejamento alimentar durante a pandemia? Concentramos nossa pesquisa no planejamento alimentar. No entanto, outros pesquisadores podem se concentrar em outros aspectos, como planejamento educacional, planejamento de trabalho remoto, planejamento de atividades físicas, apenas para citar alguns exemplos.

A abordagem participativa é inquestionável e legítima (Eden e Sims, 1981) para um desfecho favorável do problema abordado de alimentação (McIntosh et al., 2010). Este trabalho inspirou-se na metodologia proposta em McKenna et al. (2018), em que foram incluídas preferências a um problema de otimização para desenvolver conceitos de energia viáveis em pequenas comunidades rurais na Alemanha. Da mesma forma, adaptou-se essa abordagem vinculando uma ferramenta multicritério participativa, Analytic Hierarchy Process (AHP), a um modelo de otimização linear, visando assim um sólido processo de decisão.

O clássico problema da dieta, em que se deseja compor uma alimentação que atenda os limites de determinados nutrientes a um custo mínimo, teve neste trabalho uma nova abordagem. Ao tratar o problema com foco no indivíduo (e não na dieta em si), através do uso de uma nova classe de funções objetivo, voltada para hábitos e preferências alimentares individuais (e não ao gosto médio popular) em dietas clínicas, Fletcher et al. (1994) revelaram a importante necessidade de se propor soluções orientadas ao paciente, que neste trabalho é refletido no grupo familiar que usufruirá da solução proposta. Em seu estudo, palatabilidade e aceitabilidade foram as subjetividades tratadas. Na metodologia que propomos aqui, a subjetividade será prévia e amplamente discutida dentro do grupo familiar antes da construção do modelo. Embora a qualidade nutricional e a viabilidade socioeconômica sejam centrais nos problemas alimentares, além das preferências individuais, também identificamos preocupações com a sustentabilidade ambiental (Van Dooren et al., 2015; Wilson et al., 2013) em busca de uma vida mais sustentável com baixo impacto ambiental.

Este trabalho inclui, além desta introdução, a seção 2 onde é descrita a metodologia proposta, cujo desenvolvimento foi detalhado na seção 3 numa aplicação realizada na unidade familiar da autora deste trabalho como projeto piloto. Os resultados e análise são apresentados na seção 4. Finalmente, na seção 5 conclui-se o trabalho incluindo limitações da pesquisa, 
recomendações para estudos futuros e outros contextos em que essa metodologia poderá ser aplicada.

\section{Metodologia}

Foi proposto aqui uma estrutura metodológica que combinou um processo participativo de tomada de decisão a um modelo de otimização linear para endereçar uma questão diária e que ficou mais evidente durante a pandemia: a alimentação predominantemente dentro de casa e em família. Incluir preferências à um problema de otimização não é uma novidade deste trabalho. McKenna et al. (2018) usaram uma abordagem similar para desenvolver conceitos factíveis de energia em pequenas comunidades rurais na Alemanha. Propomos aqui uma adaptação deste modelo. Na Figura 1, é apresentada uma representação esquemática da estrutura metodológica sugerida, a qual conta com três fases principais. A fase 1 é composta por três encontros do grupo familiar, que chamamos de workshops e que tinham tarefas bem definidas em cada uma delas, as quais são descritas a seguir:

- Primeiro workshop: Este primeiro encontro teve como objetivo introduzir o assunto e o processo em que todos seriam convidados a participar. Além disso, foram compartilhadas as condições atuais sobre o distanciamento social, incluindo a interrupção das atividades externas, como escola, esportes, restaurantes, passeios e caminhadas. Em seguida, propusemos algumas perguntas para iniciar uma discussão aberta com foco na alimentação durante esse período. Dentre tais questões, estão listadas aqui algumas delas: O que agradaria a cada um? Quais seriam os pedidos especiais de cada um? E as restrições? O que seria importante durante esse periodo de confinamento? O fundamental aqui era falar abertamente sobre o significado da alimentação para cada um durante o período de quarentena. O resultado esperado deste workshop inicial foi a definição de uma árvore de valores e atributos que seriam considerados nas próximas etapas.

Figura 1: Estrutura metodológica.

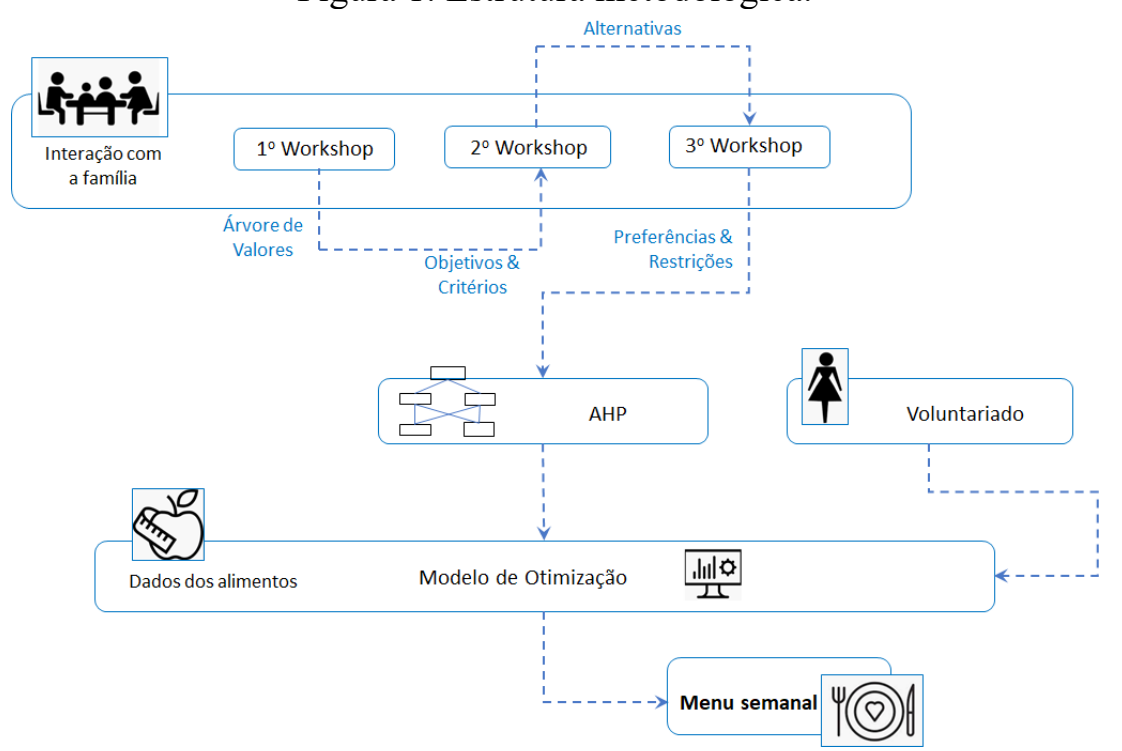

Fonte: Elaborada pela autora.

- Segundo workshop: Um esboço de um cardápio com base nas informações do workshop anterior e da rotina do grupo familiar foi apresentado para discussão e validação entre os membros. $\mathrm{O}$ objetivo deste encontro era acordar um número limitado de alternativas possíveis e agradáveis para cada refeição diária composta por café da manhã, almoço, lanche da tarde e jantar. A composição da alimentação diária pode ser adaptada a cada 
contexto familiar em análise, como a exclusão de certas refeições ou mesmo inclusão de outras, por exemplo, brunch (refeição que engloba o café da manhã e almoço simultaneamente), lanche da manhã, ceia.

- Terceiro workshop (individual): O cardápio definitivo para a semana em planejamento foi elaborado com base nas informações do workshop anterior e apresentado individualmente a cada membro do grupo familiar os quais declararam suas preferências em um processo de comparação par a par. Decidimos adotar a abordagem individual (em vez de grupo), já que, em geral, um grupo familiar não costuma ser tão numeroso e seria conveniente respeitar e acomodar a opinião de cada um.

O método de Análise Hierárquica, conhecido como AHP (Analytic Hierarchy Process), foi selecionado como ferramenta de análise de decisão multicritério a ser aplicado na fase 2. Desenvolvido na década de 1980 por Saaty $(1980,2000)$, AHP tem sido largamente adotado para resolver problemas em vários domínios e contextos, tais como: economia e planejamento, política energética, manuseio e compra de materiais, seleção de projetos, seleção de fornecedores, alocações e previsões orçamentárias (Goodwin e Wright, 2004), seleção de robôs (Goh, 1997), avaliação de qualidade (Bang e Chang, 2013), processo de seleção de gerentes (Varajão e Cruz-Cunha, 2013), comportamento de consumidores (Abuabara et al., 2019), cadeia de suprimentos (Mathiyazhagan et al., 2014), dentre tantos outros. Emrouznejad e Marra (2017) fornecem uma análise substancial sobre a base de conhecimento sobre AHP a partir de publicações entre 1979 e 2017, o qual inclui a avaliação de 8.441 artigos. A execução inicia com a construção de matrizes que expressam os valores relativos de um conjunto de atributos par a par, que é uma forma simples para qualquer indivíduo avaliar, reduzindo-se a complexidade de uma decisão e tratando aspectos subjetivos e objetivos do processo decisório (Saaty, 1980, 2000). Existem alguns pacotes computacionais desenvolvidos para auxiliar na aplicação de AHP, por exemplo Expert Choice (Goodwin e Wright, 2004) e Super Decision. No entanto, usamos aqui planilhas em Excel.

A seguir, detalhamos alguns conceitos algébricos da modelagem matemática por trás do processo AHP. Partimos da árvore de decisão, estrutura hierárquica composta por objetivo com $m$ critérios e $n$ alternativas a serem avaliadas. A partir daí, quatro passos são seguidos:

\section{(i) Cálculo dos vetores de prioridades}

Primeiramente, construímos a matriz quadrada $\boldsymbol{A}$ de tamanho $m$ x $m$, com elementos $a_{j k}$, os quais denotam o nível de importância par a par do $j$-ésimo critério em relação ao $k$-ésimo critério à luz do objetivo, de acordo com a escala numérica de 1 à 9 , conforme mostra a Tabela 4 do Apêndice. Se $a_{j k}>1$, então o $j$-ésimo critério é mais importante do que o $k$-ésimo critério, enquanto, se $a_{j k}<1$, então o $j$-ésimo critério é menos importante que o $k$-ésimo critério. No caso de dois critérios terem o mesmo nível de importância, então o atributo $a_{j k}$ será igual a 1. Evidentemente, os elementos da diagonal $(j=k)$ terão valor igual à 1 . Os atributos $a_{j k}$ e $a_{k j}$ devem satisfazer a seguinte restrição:

$$
a_{j k} \cdot a_{k j}=1 \text {. }
$$

A matriz $\boldsymbol{A}$ é então normalizada, fazendo-se com que a soma dos atributos de cada coluna seja igual a 1 . Ou seja, cada atributo $\bar{a}_{j k}$ da matriz $\boldsymbol{A}_{\text {norm }}$ (matriz de comparação normalizada) é calculado conforme a seguir:

$$
\bar{a}_{j k}=\frac{a_{j k}}{\sum_{l=1}^{m} a_{l k}} .
$$


Finalmente, o vetor prioridade dos critérios $\boldsymbol{w}, m$-dimensional, é calculado através da média dos atributos em cada linha de $\boldsymbol{A}_{\text {norm }}$, ou seja:

$$
w_{j}=\frac{\sum_{l=1}^{m} \bar{a}_{j l} .}{m} .
$$

De modo análogo, construímos as matrizes de comparação par a par $B^{(j)}$ para cada critério $m, j=1, \ldots, m$. As matrizes $B^{(j)}$ têm tamanho $n \times n$, onde $n$ é o número de opções em avaliação. Cada atributo $b_{i h}^{(j)}$ da matriz $B^{(j)}$ representa a avaliação da $i$ ésima opção comparada à $h$-ésima opção (par a par) em relação ao $j$-ésimo critério, de acordo com a escala numérica de 1 à 9 , conforme mostra a Tabela 4 do Apêndice. Se $b_{i h}^{(j)}>1$, então a $i$-ésima opção é melhor do que a h-ésima opção, enquanto se $b_{i h}^{(j)}<1$, então a $i$-ésima opção é pior que a $h$-ésima opção. Se duas opções são consideradas equivalentes em relação a um determinado $j$-ésimo critério, então o $b_{i h}^{(j)}$ atributo será igual à 1 . Além disso, os elementos da diagonal $(i=h)$ terão valor igual à 1 . Os atributos $b_{i h}^{(j)}$ e $b_{h i}^{(j)}$ devem satisfazer a seguinte restrição:

$$
b_{i h}^{(j)} \cdot b_{h i}^{(j)}=1 .
$$

Para todas as matrizes $B^{(j)}$, seguimos o mesmo procedimento de normalização, assim como feito para a matriz $\boldsymbol{A}$. Ou seja, dividimos cada atributo pela soma dos atributos da mesma coluna, e então faz-se a média dos atributos em cada linha, obtendo assim os vetores prioridades das opções $s^{(j)}, j=1, \ldots, m$. O vetor $s^{(j)}$ contém as pontuações das alternativas avaliadas com respeito ao $j$-ésimo critério. Desta forma, obtemos a matriz de pontuação $S$.

\section{(ii) Cálculo da matriz de pontuação das opções}

A matriz de pontuação das opções, denominada $\boldsymbol{S}$, tem tamanho $n \times m$. Cada atributo $S_{i j}$ de $S$ representa a pontuação da i-ésima opção em relação ao j-ésimo critério. $\mathrm{Na}$ matriz de pontuação $\boldsymbol{S}$, a $j$-ésima coluna corresponde à $S^{(j)}$, como segue:

$$
S=\left[\begin{array}{lll}
s^{(1)} & \ldots & s^{(m)}
\end{array}\right] .
$$

\section{(iii) Classificação das opções}

Uma vez calculados o vetor peso $\boldsymbol{w}$ e a matriz de pontuação $\boldsymbol{S}$, o produto matricial destes resultará no vetor $\boldsymbol{v}$ de pontuação global:

$$
v=S \cdot w .
$$

A $i$-ésima entrada $v_{i}$ de $v$ representa a pontuação global atribuída pelo AHP à $i$ ésima opção.

\section{(iv) Verificação da consistência}

Verificamos a consistência das matrizes $\boldsymbol{A}$ e $B^{(j)}$, pois algumas inconsistências no processo de comparação par a par podem ocorrer. O Índice de Consistência (IC) é obtido calculando primeiramente o escalar $\boldsymbol{x}$ como a média dos elementos do vetor cujo $j$-ésimo elemento é a razão do $j$-ésimo elemento do vetor $\boldsymbol{A} \cdot \boldsymbol{w}$ ao elemento correspondente do vetor $\boldsymbol{w}$. Desta forma: 


$$
I C=\frac{x-m}{m-1}
$$

No caso das matrizes $B^{(j)}$, substituímos $w$ por $s^{(j)}$ e $m$ por $n$.

O valor de IC será utilizado na obtenção da Taxa de Consciência (TC), determinada pela razão entre o IC e o índice de consistência aleatória (RI) obtido na Tabela 5 do Apêndice. Recomenda-se que a matriz seja considerada consistente se a razão for menor que $10 \%$. Logo,

$$
T C=\frac{I C}{R I}<0.110 \%
$$

Os julgamentos feitos de forma adequada asseguram consistência ao processo de análise usando-se AHP, logo este processo deve ser considerado de fundamental importância para sucesso do método (Godoi, 2014). No entanto, no decorrer do processo, pesos distorcidos podem ocorrer, gerando inconsistência e até mesmo a indicação de uma alternativa inadequada. Neste caso, é preciso refazer os julgamentos junto aos envolvidos.

Na fase 3, um modelo de otimização foi formulado e implementado de acordo com as informações levantadas nas etapas anteriores. O problema clássico da dieta, em que a função objetivo é minimizar o custo, está sujeita aqui às preferências do grupo familiar em particular.

Adicionalmente às informações da unidade familiar, tivemos um input externo, que deverá ser vinculado ao modelo. Semanalmente (eventualmente diariamente, mas com processamento semanal ou de acordo com os planos de saídas), recebíamos a lista de compras de nossa vizinha. $\mathrm{O}$ valor gasto com as compras dela foi totalmente reembolsado, portanto, não afetou o orçamento familiar. No entanto, o peso extra nas sacolas de compras teve que ser considerado. Essa assistência voluntária foi bastante comum durante o período da pandemia, não apenas apoiando os vizinhos, mas também familiares e amigos idosos, ou mesmo assistindo famílias mais carentes, por meio da doação de alimentos. Essas questões, particulares de cada núcleo familiar, podem fazer parte do modelo.

\section{Desenvolvimento da Modelagem Matemática}

O grupo familiar em confinamento na mesma residência, e onde o modelo foi aplicado, era composto por dois adultos e duas crianças. A participação de todos foi ativa durante todo o processo. O primeiro workshop ocorreu uma semana após o início do decreto de quarentena. Esta foi uma discussão aberta, recebida com grande entusiasmo por todos os membros os quais estavam felizes e se sentindo importantes em participar do projeto. Um dos membros, que passou do trabalho predominantemente presencial para o home-office, percebeu-se livre para comer porcarias e beliscar com mais frequência, mesmo acreditando que isso não seria bom no longo prazo. Outro membro, preocupado com o excesso de peso após o período de quarentena, sugeriu que as sobremesas fossem abolidas durante esse período. $\mathrm{O}$ mais jovem só queria fazer refeições gostosas todos os dias. Este argumento é muito subjetivo, e, portanto, será endereçado pelo método AHP. Outro membro, responsável pelas compras, declarou-se preocupado em manter um bom estoque de comida. Porém, não havia razão para isso. Apesar de termos que reduzir o número de idas ao supermercado, não precisaríamos nos privar de alimentos frescos. $\mathrm{O}$ suprimento não seria um problema. No entanto, os supermercados estavam limitando o número de clientes que poderiam permanecer no interior dos estabelecimentos. Uma vez dentro, deveríamos focar e selecionar os produtos o mais rápido possível a fim de se minimizar os riscos de contágio também. Logo, ter em mãos uma lista de compras previamente planejada nos faria mais eficientes. Após uma conversa muito produtiva, finalizamos este primeiro workshop 
com os valores e atributos ilustrados na Figura 2. Essa árvore foi compartilhada e validada junto à família antes do início do segundo workshop.

Figura 2: Árvore de valores e atributos após primeiro workshop.

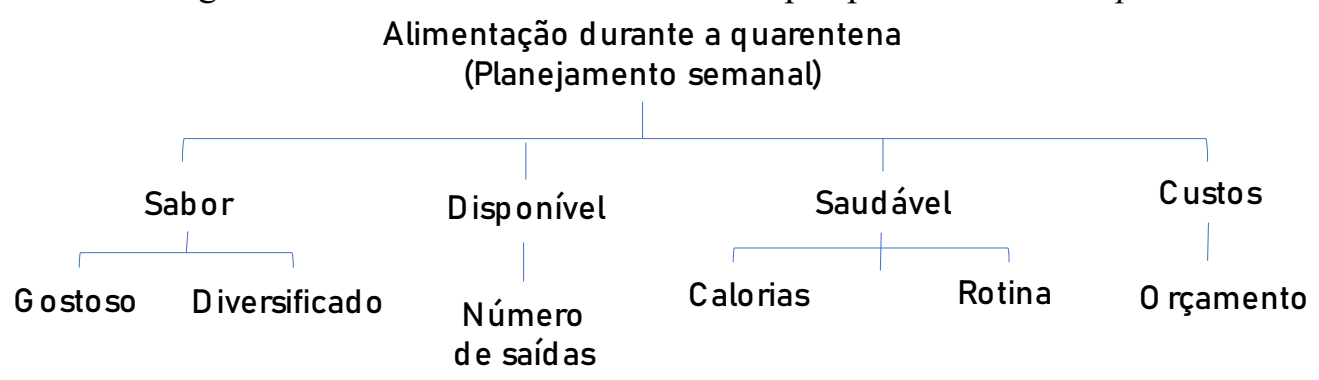

Fonte: Elaborada pela autora.

No período entre o primeiro e o segundo workshop, foi preparada uma lista de refeições completas com base na rotina usual de cozinhar em casa da unidade familiar. Após discussão, ajuste e validação, finalizamos com uma lista de quatro (4) alternativas para o café da manhã, cinco (5) alternativas para o almoço, quatro (4) alternativas para o lanche da tarde, quatro (4) alternativas para o jantar e, três (3) alternativas de delivery. As informações sobre cada refeição estão disponíveis na Tabela 3 no Apêndice, a qual inclui preço médio de compra (BRL) no mercado local, calorias (kcal) informadas pelo fabricante nas embalagens, e, quantidade $(\mathrm{kg})$ geralmente consumida por toda a unidade familiar em cada refeição. Algumas refeições foram classificadas de forma flexível caso pudessem atender alternativamente mais de um tipo de refeição (por exemplo, podíamos pedir certos deliveries para o almoço ou jantar, e, ter certas opções de lanche no café da manhã e vice-versa. Começou-se também, neste momento, a modelar nosso problema. Os atributos: diversificado, número de saidas, calorias, rotina e orçamento foram considerados como restrições do problema. O atributo mais subjetivo, que foi a designação do sabor da refeição como sendo gostosa fez parte da função objetivo. Dentro do método AHP, ser gostoso tornou-se o objetivo. As quatro refeições entraram como critérios, e, as opções de refeição serviram de alternativas. A Figura 3 ilustra este modelo em AHP. As opções de refeição (alternativas) foram avaliadas durante o terceiro workshop no processo AHP.

Figura 3: Árvore de decisão para o modelo AHP.

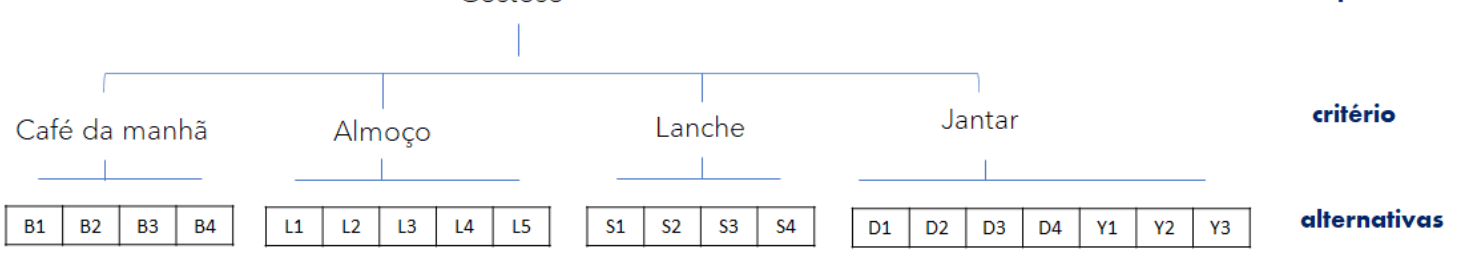

Fonte: Elaborada pela autora.

Durante o terceiro workshop, foi aplicado o processo AHP com cada membro do grupo familiar individualmente. Iniciou-se explicando como os pesos deveriam ser atribuídos, e cada um dos membros atribuiu seus pesos comparando cada par de refeições (café, almoço, lanche e jantar) à luz do objetivo (gostoso), e, cada par de alternativas à luz dos critérios. Os julgamentos paritários foram feitos através da atribuição de um valor entre 1 e 9, sendo que o valor 1 designa igual importância entre as opções ('tanto faz!'), e, 9 designa importância absoluta ('meu prato preferido!'). Esta foi uma oportunidade de captar as opiniões individuais em relação ao atributo gostoso, uma característica bastante singular de cada um. As matrizes com os julgamentos de cada membro estão reportadas no Apêndice (Matriz 1 à Matriz 20). A Tabela 1 resume a classificação global individual de cada membro e o valor total do grupo familiar através da 
soma dos valores individuais. As informações desta tabela formaram o vetor de pesos para o atributo gostoso, sendo este o parâmetro usado para as variáveis de decisão na função objetivo.

Tabela 1: Classificação global individual e total das refeições.

\begin{tabular}{|c|c|c|c|c|c|}
\hline Opção $i$ & Membro \#1 & Membro \#2 & Membro \#3 & Membro \#4 & Total $\left(w_{i}\right)$ \\
\hline B1 & 0,063 & 0,023 & 0,011 & 0,058 & 0,155 \\
\hline B2 & 0,021 & 0,065 & 0,005 & 0,027 & 0,119 \\
\hline B3 & 0,148 & 0,255 & 0,029 & 0,034 & 0,465 \\
\hline B4 & 0,278 & 0,191 & 0,074 & 0,196 & 0,739 \\
\hline L1 & 0,007 & 0,005 & 0,012 & 0,027 & 0,052 \\
\hline L2 & 0,005 & 0,002 & 0,009 & 0,007 & 0,024 \\
\hline L3 & 0,047 & 0,007 & 0,010 & 0,005 & 0,069 \\
\hline L4 & 0,012 & 0,016 & 0,013 & 0,002 & 0,043 \\
\hline L5 & 0,026 & 0,031 & 0,017 & 0,019 & 0,093 \\
\hline S1 & 0,066 & 0,015 & 0,154 & 0,058 & 0,292 \\
\hline S2 & 0,011 & 0,029 & 0,078 & 0,201 & 0,318 \\
\hline S3 & 0,033 & 0,059 & 0,027 & 0,022 & 0,141 \\
\hline S4 & 0,129 & 0,169 & 0,400 & 0,232 & 0,930 \\
\hline D1 & 0,020 & 0,007 & 0,007 & 0,005 & 0,039 \\
\hline D2 & 0,006 & 0,015 & 0,017 & 0,028 & 0,066 \\
\hline D3 & 0,017 & 0,005 & 0,004 & 0,022 & 0,047 \\
\hline D4 & 0,026 & 0,003 & 0,017 & 0,003 & 0,049 \\
\hline Y1 & 0,061 & 0,032 & 0,038 & 0,007 & 0,137 \\
\hline Y2 & 0,018 & 0,046 & 0,064 & 0,015 & 0,142 \\
\hline Y3 & 0,004 & 0,026 & 0,016 & 0,033 & 0,079 \\
\hline & 1,000 & 1,000 & 1,000 & 1,000 & 4,000 \\
\hline
\end{tabular}

Fonte: Elaborada pela autora.

Para a formulação matemática do problema considere os seguintes parâmetros:

$i=\{1, \ldots, R\}: \quad$ conjunto de alternativas;

$j=\{1, \ldots, N\}$ : conjunto de refeições;

$w_{i}: \quad$ peso (resultado do AHP) atribuído à cada alternativa $i$;

$p_{i}: \quad$ peso (em $\left.\mathrm{kg}\right)$ de cada alternativa $i$;

$c_{i}$ : $\quad$ calorias de cada alternativa $i$

$b_{i}: \quad$ custo estimado de cada alternativa $i$;

P: $\quad$ carga total suportada nas compras da semana;

$C$ : $\quad$ calorias recomendadas para o grupo familiar na semana;

B: $\quad$ orçamento disponível semanal;

M: $\quad$ quantidade da refeição $j$ servidas na semana;

$L_{R} \quad$ quantidade da alternativa $i$ (preparada em casa) repetida na mesma

$L_{D} \quad$ quantidade da alternativa $i$ (delivery) repetida na mesma semana.

As variáveis de decisão são definidas por:

$x_{i j}$ : $\quad$ quantidade de alternativas $i$ servidas durante a semana na refeição $j$.

A formulação do problema é dada por: 


$$
\text { Maximizar } \sum_{j=1}^{N} \sum_{i=1}^{R} w_{i} \cdot x_{i j} \text {. }
$$

Sujeito à:

$$
\begin{array}{ll}
\sum_{i=1}^{R} \sum_{j=1}^{N} p_{i} \cdot x_{i j} \leq P, & i=1, \ldots, R \\
\sum_{i=1}^{R} \sum_{j=1}^{N} c_{i} \cdot x_{i j} \leq C, & j=1, \ldots, N \\
\sum_{i=1}^{R} x_{i j}=M_{j}, & i=1, \ldots, R \\
\sum_{i=1}^{R} \sum_{j=1}^{N} b_{i} \cdot x_{i j} \leq W & j=1, \ldots, N \\
\sum_{j=1}^{N} x_{i j} \leq L_{R}, & i=1, \ldots, N \\
\sum_{j=1}^{N} x_{i j} \leq L_{D}, & j=1, \ldots, N \\
x_{i j} \geq 0 e x_{i j} \in Z & i=1, \ldots, 17 \\
i \in\{1, \ldots, R\} \quad e \quad j \in\{1, \ldots, N\}, &
\end{array}
$$

Nesse caso em particular, o horizonte de planejamento abrangeu apenas uma semana (período de sete dias). A intenção é replicar o padrão semanal de alimentação durante a quarentena, substituindo apenas pratos equivalentes como polenta por cuscuz, biscoitos por bolo, frutas da estação, açaí por creme de abacate, diferentes molhos para as massas, diferentes massas, a fim de se manter uma maior variedade.

A função objetivo (9) é maximizar a satisfação do grupo familiar em relação à alimentação, especialmente atrelada ao atributo gostoso, o que é dado pela soma dos valores dos pesos atribuídos à cada alternativa $i$ multiplicados pela quantidade de refeições $j$ servidas na semana. Os demais atributos foram considerados entre as restrições do modelo.

A seguir são apresentados mais detalhes sobre as restrições do modelo:

\section{a. Peso das sacolas de compras}

A restrição (10) teve duas especificidades: (i) a primeira foi dar prioridade em fazer as compras em estabelecimentos próximos. Além de fortalecer a economia local, frequentar supermercados, mercearias, hortifrutis que estavam a uma curta distância de casa e que fosse possível ir caminhando daria a oportunidade de incluir algum movimento ao ar livre nos dias predominantemente confinados; (ii) a segunda foi a inclusão do peso das compras de nossa vizinha. O limite considerado foi um total de $45 \mathrm{~kg}$ por semana. Esse número levou em conta três saídas semanais em que era possível carregar $15 \mathrm{~kg}$ em cada uma. No entanto, reservamos um total de $10 \mathrm{~kg}$ para as compras dela. Produtos de limpeza e higiene pessoal não foram considerados nesta rotina de compras. Além disso, o café era comprado via internet. Os valores de $p_{i}$, em quilogramas, de cada alternativa $i$ estão listados na Tabela 3 no Apêndice.

\section{b. Consumo diário de calorias}

A contagem de calorias é apenas um dos muitos sinais metabólicos a serem controlados. Existem outros tais como carboidratos, gorduras, proteínas, minerais e vitaminas. No entanto, controle do consumo calórico foi o único item abordado durante o processo participativo e, desta forma, considerado no modelo. A razão por trás disso pode ser justificada, pois esse sinal 
metabólico está bastante ligado ao sinal sensorial do paladar (Jacobs e Sharma, 1969). A ingestão ideal de calorias deve considerar a idade, o metabolismo, a intensidade de atividade física, entre outros aspectos do indivíduo. A fim de se estabelecer um limite para a ingestão calórica familiar, usamos calculadoras dedicadas para crianças (BCM, 2020a) e adultos (BCM, 2020b), fornecidas pelo Baylor College of Medicine, com as quais pôde-se ter uma ordem de grandeza do consumo calórico de cada membro da família de acordo com sexo (feminino/masculino), peso corporal $(\mathrm{kg})$, altura $(\mathrm{cm})$, idade (anos) e perfil de atividade física (baixo/moderado/intenso). Este último foi considerado baixo para todos os membros devido às medidas quarentenárias de confinamento. $\mathrm{O}$ resultado foi uma ingestão de 1.903 calorias para o membro \#1; 2.519 calorias para o membro \#2; 2.147 calorias para o membro \#3; e 1.728 para o membro \#4. A quantidade total de consumo calórico familiar foi 8.297 por dia. Em termos de consumo semanal, temos 58.079 calorias. A contagem das calorias de forma agregada, não parametrizando o consumo energético diário nem individual, é uma limitação deste estudo. Por outro lado, um balanço semanal foi estabelecido. Além disso, criar variáveis para cada indivíduo não faria sentindo no contexto, pois não fez parte das possibilidades oferecer pratos individuais. Os valores de $c_{i}$ da restrição (11), em quilocalorias, de cada alternativa $i$ estão listados na Tabela 3 no Apêndice.

\section{c. Rotina}

A forma de garantir que a rotina fosse mantida foi servindo todos os dias da semana $\left(M_{j}\right.$ =7) as quatro refeições diárias (café da manhã, almoço, lanche e jantar) em horário usual e conveniente à família dada pela restrição (12). O horário não foi contemplado no modelo. Além disso, algumas refeições puderam ser intercambiadas, como pedir certos deliveries no almoço.

\section{d. Orçamento}

O valor orçamentário destinado à alimentação foi limitado à BRL 600 semanais, quantidade considerada razoável de acordo com pesquisa de orçamento familiar realizada pelo Instituto Brasileiro de Geografia e Estatística (IBGE, 2019). Neste valor não estão incluídos os gastos com material de limpeza e higiene pessoal, o café e as compras de nossa vizinha. Os valores de $b_{i}$ da restrição (13), em Reais, o qual compõe o custo estimado de cada alternativa $i$, encontram-se disponíveis na Tabela 3 no Apêndice.

\section{e. Diversidade}

Demos significado a essa restrição limitando-se a quantidade alternativas sendo repetidas durante a semana. Ao repetir um prato ao longo da semana, economiza-se tempo cozinhando de uma única vez uma quantidade maior. No entanto, este era algo que gostaríamos de evitar sem ser completamente intransigentes, já que em alguns dias da semana é preciso ser muito práticos para dar conta de todas as atividades previstas. Desta forma, foi feita a seguinte consideração: os pedidos de delivery estariam limitados a um por semana cada um $\left(L_{D}=1\right)$ : restrição $(15)$; as demais opções estariam limitadas à três vezes por semana $\left(L_{R}=3\right)$ : restrição (14).

\section{f. Domínio das variáveis}

Finalmente, as restrições (16) definem os domínios das variáveis de decisão de nãonegatividade e integralidade. Além disso, como dado em (17), o modelo incluiu 20 alternativas $(R=20)$ em 4 refeições diárias $(N=4)$, representando café da manhã, almoço, lanche e jantar, respectivamente.

\section{Resultados e Análise}

O modelo foi implementado em linguagem Python, usando-se a biblioteca PuLP. A Tabela 2 apresenta os resultados obtidos para o modelo original e para algumas simulações adicionais feitas a partir do cálculo do preço-sombra dos recursos peso, calorias e preço. A seguir, tais análises são descritas com mais detalhes: 
i. O aumento de uma unidade de peso ao lado direito da inequação-restrição, incrementa a função objetivo em $0,006 / \mathrm{kg}$ (preço-sombra do recurso peso). Isto nos leva a considerar um possível peso extra, o qual poderia ser viabilizado aumentando-se o número de saídas ou indo de carro às compras ou, ainda, incluindo uma compra com entrega em domicílio (com possível custo adicional de entrega). As duas primeiras alternativas aumentam a exposição ao risco de contaminação do vírus, enquanto a terceira, a qual vem sendo bastante praticada nesses tempos, poderia não atender o prazo de planejamento ou gerar um custo adicional. Simulou-se, a partir do modelo original, uma saída adicional, elevando o peso de $35 \mathrm{~kg}$ para $50 \mathrm{~kg}$ semanais (simulação 1 ).

ii. Do ponto de vista do consumo calórico, o preço-sombra desta restrição foi nulo, logo é dita uma restrição não-ativa (folga $>0$ ). Neste contexto, abrir exceção para mais doces, por exemplo, não aumentaria o valor da função objetivo e, portanto, a satisfação da família. Esta constatação pode ter um significado positivo, pois apesar de termos considerado um perfil baixo de atividades físicas ao contabilizar o consumo calórico alocado na restrição, o confinamento foi bastante restritivo, especialmente devido ao fechamento de escolas e parques públicos, limitando em muito a movimentação, especialmente das crianças.

iii. Do ponto de vista das restrições orçamentárias, esta é uma restrição ativa e pode melhorar o valor da função objetivo caso se destine mais recursos à alimentação. $\mathrm{O}$ preço-sombra deste recurso é 0,002 / BRL. Simulou-se, a partir do modelo original, um orçamento adicional de $50 \mathrm{BRL}$ por semana. $\mathrm{O}$ resultado foi ainda mais satisfatório (simulação 2).

Por fim, conciliou-se numa nova simulação o peso e o orçamento semanal adicional (simulação 3) sem grandes ganhos adicionais.

Tabela 2: Resultados e simulações.

\begin{tabular}{|c|c|c|c|c|c|}
\hline & $\begin{array}{c}\text { Model } \\
0\end{array}$ & Original & $\begin{array}{l}\text { Simulação } 1 \\
\text { (Peso=50kg) }\end{array}$ & $\begin{array}{c}\text { Simulação } 2 \\
\text { (Preço=BRL650) }\end{array}$ & $\begin{array}{c}\text { Simulação } 3 \text { (50kg } \\
\text { + BRL650) }\end{array}$ \\
\hline \multirow{3}{*}{$\begin{array}{l}\text { Café da } \\
\text { manhã }\end{array}$} & $x_{11}$ & 1 & 1 & 1 & 1 \\
\hline & $x_{31}$ & 3 & 3 & 3 & 3 \\
\hline & $x_{41}$ & 3 & 3 & 3 & 3 \\
\hline \multirow{4}{*}{ Almoço } & $x_{72}$ & 2 & 1 & 2 & 2 \\
\hline & $x_{82}$ & 3 & 3 & 3 & 3 \\
\hline & $x_{152}$ & 0 & 2 & 0 & 0 \\
\hline & $x_{162}$ & 2 & 1 & 2 & 2 \\
\hline \multirow{3}{*}{ Lanche } & $x_{103}$ & 1 & 1 & 1 & 1 \\
\hline & $x_{113}$ & 3 & 3 & 3 & 3 \\
\hline & $x_{133}$ & 3 & 3 & 3 & 3 \\
\hline \multirow{6}{*}{ Jantar } & $x_{94}$ & 3 & 3 & 3 & 3 \\
\hline & $x_{164}$ & 1 & 2 & 1 & 1 \\
\hline & $x_{174}$ & 1 & 0 & 0 & 0 \\
\hline & $X_{184}$ & 1 & 1 & 1 & 1 \\
\hline & $X_{194}$ & 0 & 0 & 1 & 1 \\
\hline & $X_{204}$ & 1 & 1 & 1 & 1 \\
\hline F.O. & & 8,755 & 8,769 & 8,848 & 8,848 \\
\hline
\end{tabular}


Fonte: Elaborada pela autora.

\section{Conclusões e Recomendações}

Boa parte da população brasileira esteve sob recomendação de confinamento por um longo período (até o momento já são mais de 200 dias). Respeitar esta condição também dependeu do tipo de trabalho exercido por cada indivíduo e a possibilidade de realizá-lo remotamente. Foram (estão sendo) tempos difíceis, alguns com perdas pessoais, desemprego, entre outras adversidades, que o período de pandemia tem nos trazido. Por outro lado, também podemos listar pontos positivos, não exatamente com mais tempo livre, mas com um tempo dedicado às atividades de forma diferente, como a leitura de mais livros, o contato remoto a velhos amigos, a maior sociabilização dentro de casa.

É tempo de ficar em casa, e esta experiência deve ser explorada de forma construtiva. É um período de intensa imersão no convívio familiar, o que inclui os momentos ao redor da mesa. As condições de confinamento tiveram algumas exceções, como as idas ao supermercado, as quais proporcionaram muitas possibilidades culinárias com criatividade. No entanto, não pudemos esquecer as atividades e obrigações profissionais e pessoais, as quais consomem muito tempo. Devido a isso, mantivemos o foco na praticidade. Foi justamente a necessidade pela simplicidade e funcionalidade, juntamente com a participação e comprometimento do grupo familiar em confinamento, que nos levou a esse projeto de desenvolver uma nova abordagem para o clássico problema da dieta, porém de forma participativa, maximizando preferências, que podem ser suficientemente subjetivas. Fomos capazes de desenvolver cardápios semanais agradáveis e listas de compras de forma rápida, além de ajudar uma vizinha. $\mathrm{O}$ processo participativo torna o mesmo legítimo e de maior chance de sucesso na prática.

Comida é afeto, é conforto. Este trabalho foi um esforço de trazer ao debate reflexões sobre o comer consciente em condições de confinamento. E que o ato de se alimentar fosse prazeroso e participativo foi o objetivo deste trabalho, mas não deixando de lado as bem objetivas restrições existentes. Esta foi uma nova abordagem para um velho problema da pesquisa operacional. Embora o modelo tenha se originado em uma época de caos e estar bastante ajustado a um caso específico, ele pode ser adaptado e aplicado em outros contextos e cenários, tais como desenvolver cardápios enxutos em restaurantes envolvendo seus clientes, ou, em hospitais envolvendo seus pacientes, ou em hotéis envolvendo seus hóspedes, ou em catering de linhas aéreas. O ambiente familiar, com poucas pessoas, também pode ser substituído por grupos maiores, sendo aplicável até mesmo a uma comunidade e para um horizonte de planejamento mais longo. Neste caso, fica a sugestão da automatização do modelo proposto.

Agradecimentos. O presente trabalho foi realizado com apoio da Coordenação de Aperfeiçoamento de Pessoal de Nível Superior - Brasil (CAPES) - Código de Financiamento 001. A autora agradece os relevantes comentários e sugestões feitos pelos revisores anônimos da revista.

\section{Referências}

Abuabara, L., Paucar-Caceres, A. e Burrowes-Cromwell, T. Consumers' values and behaviour in the Brazilian coffee-in-capsules market: promoting circular economy. International Journal of Production Research, v. 57, n. 23, p. 7269-7288, 2019.

Assis, M. A. A. de e Nahas, M. V. Aspectos motivacionais em programas de mudança de comportamento alimentar. Revista de Nutrição, v. 12, n. 1, p. 33-41, 1999.

Bang, W. e Chang, B.-Y. Quality factor analysis of metalworking process with AHP. International Journal of Production Research, v. 51, n. 19, p. 5741-5756, 2013. 
BCM - Baylor College of Medicine. Adult energy needs and BMI calculator. 2020a. Disponível em: https://www.bcm.edu/cnrc-apps/caloriesneed.cfm. Acesso em: 09/06/2020.

BCM - Baylor College of Medicine. Children's energy needs calculator. 2020b. Disponível em: https://www.bcm.edu/cnrc-apps/bodycomp/energy/energyneeds_calculator.htm. Acesso em: 09/06/2020.

Coll, L. Hábitos saudáveis diminuíram e estados de ânimo pioraram durante pandemia. 2020. Faculdade de Ciências Médicas, UNICAMP. Disponível em: https://www.unicamp.br/unicamp/noticias/2020/06/09/habitos-saudaveis-diminuiram-e-estadosde-animo-pioraram-durante-pandemia. Acesso em: 12/07/2020.

Di Renzo, L., Gualtieri, P., Pivari, F., Soldati, L., Attinà, A., Cinelli, G. et al. Eating habits and lifestyle changes during COVID-19 lockdown: An Italian survey. Journal of Translational Medicine, v. 18, p. 1-15, 2020.

Dou, Z., Stefanovski, D., Galligan, D., Lindem, M., Rozin, P., Ting, C. et al. The COVID-19 pandemic impacting household food dynamics: A cross-national comparison of China and the U.S. SocArXiv, 2020.

https://doi.org/10.31235/osf.io/64jwy

Eden, C. e Sims, D. Management science process-subjectivity in problem identification. Interfaces, v. 11, n. 1, p. 68-74, 1981.

Emrouznejad, A. e Marra, M. The state-of-the-art development of AHP (1979-2017): A literature review with a social network analysis. International Journal of Production Research, v. 55, n. 22 , p. $6653-6675,2017$.

Fletcher, L. R., Soden, P.M. e Zinober, A. S. I. Linear programming techniques for the construction of palatable human diets. Journal of the Operational Research Society, v. 45, n. 5, p. 489-496, 1994.

Godoi, W.C. Método de construção das matrizes de julgamento paritários no AHP - método de julgamento holístico. Revista Gestão Industrial, v. 10, n. 3, p. 474- 493, 2014.

Goh, C.-H. Analytic hierarchy process for robot selection. Journal of Manufacturing Systems, v. 16, n. 5, p. 381-386, 1997.

Goodwin, P. e Wright, G. Decision Analysis for Management Judgment. $3^{\mathrm{a}}$ ed. Chichester: John Wiley \& Sons, 2004.

IBGE - Instituto Brasileiro de Geografia e Estatística. Pesquisa de Orçamentos Familiares 2017-2018 - Primeiros Resultados. 2019. Disponível em: https://biblioteca.ibge.gov.br/visualizacao/livros/liv101670.pdf. Acesso em: 27/11/2020.

Jackson-Morris, A. M., Nugent, R., Ralston, J., Barata Cavalcante, O. e Wilding, J. Strengthening resistance to the COVID-19 pandemic and fostering future resilience requires concerted action on obesity. Global Health Action, v. 13, n. 1, 1804700, 2020.

Jacobs, H. L. e Sharma, K. N. Taste versus calories: sensory and metabolic signals in the control of food intake. Annals of the New York Academy of Sciences, v. 157, n. 2, p. 1084-1125, 1969.

Jovančević, A. e Milićević, N. Optimism-pessimism, conspiracy theories and general trust as 
factors contributing to COVID-19 related behavior - A cross-cultural study. Personality and Individual Differences, v. 167, 110216, 2020. https://doi.org/10.1016/j.paid.2020.110216.

Laguna, L., Fiszman, S., Puerta, P., Chaya, C. e Tárrega, A. The impact of COVID-19 lockdown on food priorities. Results from a preliminary study using social media and an online survey with Spanish consumers. Food Quality and Preference, v. 86, 104028, 2020. https://doi.org/10.1016/j.foodqual.2020.104028.

Maciel, M. E. e de Castro, H. C. A comida boa para pensar: sobre práticas, gostos e sistemas alimentares a partir de um olhar socioantropológico. Demetra: alimentação, nutrição e saúde, v. 8, supl. 1, p. 321-328, 2013.

Mathiyazhagan, K., Govindan, K. e Haq, A. N. Pressure analysis for green supply chain management implementation in Indian industries using analytic hierarchy process. International Journal of Production Research, v. 52, n. 1, p. 188-202, 2014.

McIntosh, W. A., Kubena, K. S., Tolle, G., Dean, W. R., Jan, J.-sheng e Anding, J. Mothers and meals. The effects of mothers' meal planning and shopping motivations on children's participation in family meals. Appetite, v. 55, n. 3, p. 623-628, 2010.

McKenna, R., Bertsch, V., Mainzer, K. e Fichtner, W. Combining local preferences with multicriteria decision analysis and linear optimization to develop feasible energy concepts in small communities. European Journal of Operational Research, v. 268, n. 3, p. 1092-1110, 2018.

Mehta, V. The impact of COVID-19 on the dietary habits of middle-class population in Mulund, Mumbai, India. AIJR Preprints, article id: 82, version: 1, p. 1-10, 2020. https://preprints.aijr.org/index.php/ap/preprint/view/82.

Ministério da Saúde. Coronavírus COVID-19: o que você precisa saber. 2020a. Disponível em: https://coronavirus.saude.gov.br/sobre-a-doenca. Acesso em: 08/07/2020.

Ministério da Saúde. Pesquisa identifica comportamentos de risco e proteção para a COVID19. 2020b. Disponível em: https://www.gov.br/saude/pt-br/assuntos/noticias/pesquisaidentifica-comportamentos-de-risco-e-protecao-para-a-covid-19. Acesso em: 06/05/2020.

Poulain, J.-P. e Proença, R. P. da C. O espaço social alimentar: um instrumento para o estudo dos modelos alimentares. Revista de Nutrição, v. 16, n. 3, p. 245-256, 2003.

Saaty, T. L. The Analytic Hierarchy Process. New York: McGraw-Hill, 1980.

Saaty, T. L. Decision Making for Leaders. Pittsburg: WS, 2000.

Tuchlinski, C. Comida e afeto: como a gastronomia está aproximando pais e filhos. 2020. Estadão, Cultura. Disponível em: https://cultura.estadao.com.br/noticias/geral,comida-e-afetocomo-a-gastronomia-esta-aproximando-pais-e-filhos,70003359906._Acesso em: 20/07/2020.

Van Dooren, C., Tyszler, M., Kramer, G. F. H. e Aiking, H. Combining low price, low climate impact and high nutritional value in one shopping basket through diet optimization by linear programming. Sustainability, v. 7, n. 9, p. 12837-12855, 2015.

Varajão, J. e Cruz-Cunha, M. M. Using AHP and the IPMA competence baseline in the project managers selection process. International Journal of Production Research, v. 51, n. 11, p. 3342-3354, 2013. 
Wilson, N., Nghiem, N., Ni Mhurchu, C., Eyles, H., Baker, M. G. e Blakely, T. Foods and dietary patterns that are healthy, low-cost, and environmentally sustainable: a case study of optimization modeling for New Zealand. PLoS ONE, v. 8, n. 3, 0059648, 2013. https://doi.org/10.1371/journal.pone.0059648

\section{Apêndice}

Tabela 3: Cardápio avaliado.

\begin{tabular}{|c|c|c|c|c|c|}
\hline Opção $i$ & Refeição $j$ & Descrição & $\begin{array}{l}\text { Peso } p_{i} \\
\text { (kg) }\end{array}$ & $\begin{array}{l}\text { Preço } b_{i} \\
\text { (BRL) }\end{array}$ & $\begin{array}{l}\text { Calorias } c_{i} \\
\text { (kcal) }\end{array}$ \\
\hline B1 (1) & $\begin{array}{l}\text { Café da manhã } \\
\text { / Lanche }\end{array}$ & $\begin{array}{c}\text { Café com leite, frutas frescas, } \\
\text { pão de queijo }\end{array}$ & 1,18 & 10,05 & $2.219,6$ \\
\hline B2 (2) & $\begin{array}{l}\text { Café da manhã } \\
\text { / Lanche }\end{array}$ & $\begin{array}{l}\text { Café, cereais com iogurte, } \\
\text { frutas frescas }\end{array}$ & 1,55 & 15,60 & $1.834,0$ \\
\hline B3 (3) & $\begin{array}{l}\text { Café da manhã } \\
\text { / Lanche }\end{array}$ & $\begin{array}{c}\text { Café com leite, frutas frescas, } \\
\text { cookie de chocolate }\end{array}$ & 1,02 & 15,40 & $1.046,0$ \\
\hline B4 (4) & $\begin{array}{l}\text { Café da manhã } \\
\text { / Lanche }\end{array}$ & $\begin{array}{l}\text { Café com leite, frutas } \\
\text { vermelhas, waffle com creme } \\
\text { de chocolate e avelã }\end{array}$ & 1,10 & 20,12 & $1.710,7$ \\
\hline L1 (5) & $\begin{array}{l}\text { Almoço / } \\
\text { Jantar }\end{array}$ & $\begin{array}{l}\text { Macarrão ao molho de tomate } \\
\text { com carne, salada }\end{array}$ & 1,71 & 39,58 & $3.284,5$ \\
\hline L2 (6) & $\begin{array}{c}\text { Almoço / } \\
\text { Jantar }\end{array}$ & $\begin{array}{l}\text { Polenta com ragu de frango, } \\
\text { salada }\end{array}$ & 1,25 & 32,02 & $1.834,0$ \\
\hline L3 (7) & Almoço & $\begin{array}{c}\text { Arroz, peixe grelhado, chips de } \\
\text { banana chips e vegetais } \\
\text { cozidos }\end{array}$ & 1,26 & 39,87 & $2.673,7$ \\
\hline L4 (8) & Almoço & $\begin{array}{l}\text { Arroz, feijão, linguiça, ovos } \\
\text { mexidos e salada }\end{array}$ & 1,09 & 10,31 & $2.490,9$ \\
\hline L5 (9) & $\begin{array}{l}\text { Almoço / } \\
\text { Jantar }\end{array}$ & Hamburguer feito em casa & 1,50 & 30,74 & $2.771,0$ \\
\hline S1 (10) & Lanche & Pipoca, suco & 1,25 & 10,10 & $1.250,0$ \\
\hline S2 (11) & Lanche & Salgadinho chips, fruta & 1,17 & 10,85 & $1.335,4$ \\
\hline S3 (12) & $\begin{array}{l}\text { Lanche / Café } \\
\text { da manhã }\end{array}$ & logurte com granola, fruta & 1,92 & 23,71 & $1.647,0$ \\
\hline S4 (13) & Lanche & Creme de açaí com leite em pó & 0,97 & 24,2 & $1.842,6$ \\
\hline D1 (14) & Jantar & Brusquetas de atum, suco & 1,37 & 37,06 & $2.007,5$ \\
\hline D2 (15) & $\begin{array}{l}\text { Jantar / } \\
\text { Almoço }\end{array}$ & Mini pizzas & 2,24 & 34,51 & $3.292,0$ \\
\hline D3 (16) & $\begin{array}{l}\text { Jantar / } \\
\text { Almoço }\end{array}$ & Sopa de legumes e torradas & 1,56 & 16,87 & $2.261,5$ \\
\hline D4 (17) & $\begin{array}{l}\text { Jantar / } \\
\text { Almoço }\end{array}$ & $\begin{array}{c}\text { Tapioca de presunto e queijo, } \\
\text { suco }\end{array}$ & 1,89 & 31,20 & $3.397,0$ \\
\hline $\begin{array}{c}\mathrm{Y} 1 \\
(18) 1^{1}\end{array}$ & Delivery & Pizza margherita, suco & 1,15 & 44,13 & $2.284,0$ \\
\hline Y2 (19) & $\begin{array}{l}\text { Delivery / } \\
\text { Almoço }\end{array}$ & $\begin{array}{c}\text { Esfihas (carne, queijo e } \\
\text { brócolis), suco }\end{array}$ & 0,60 & 78,36 & $2.760,0$ \\
\hline Y3 (20) & $\begin{array}{l}\text { Delivery / } \\
\text { Almoço }\end{array}$ & Hamburguers, refrigerante & 0,60 & 37,80 & $2.231,0$ \\
\hline
\end{tabular}

Fonte: Elaborado pela autora.

1 Somente a bebida é considerada no peso. 


\section{Escala fundamental de Saaty}

Tabela 4: Escala fundamental de Saaty (adaptado de Saaty, 1980).

\begin{tabular}{|c|c|}
\hline Valor de $\boldsymbol{a}_{\boldsymbol{j} \boldsymbol{k}}$ & Interpretação \\
\hline 1 & $j$ e $k$ são igualmente importantes \\
\hline 3 & $j$ é levemente mais importante do que $k$ \\
\hline 5 & $j$ é mais importante do que $k$ \\
\hline 7 & $j$ é fortemente mais importante do que $k$ \\
\hline 9 & $j$ é absolutamente mais importante do que $k$ \\
\hline $2,4,6,8$ & Valores intermediários \\
\hline
\end{tabular}

Tabela 5: Valores do Índice Aleatório (RI) para pequenos problemas (fonte: Saaty, 1980).

\begin{tabular}{|c|c|c|c|c|c|c|c|c|c|}
\hline $\mathbf{m}$ & 2 & 3 & 4 & 5 & 6 & 7 & 8 & 9 & 10 \\
\hline $\mathbf{R I}$ & 0 & 0.58 & 0.90 & 1.12 & 1.24 & 1.32 & 1.41 & 1.45 & 1.51 \\
\hline
\end{tabular}

\section{Matrizes de comparação pareada}

1. Julgamentos dos critérios em relação ao objetivo. Qual refeição do dia mais aprecia?

Matriz 1: Comparação par a par dos critérios à luz do objetivo do membro \#1.

Objetivo
Café manhã
Almoço
$\begin{gathered}\text { Lanche } \\ \text { Jantar }\end{gathered}$$\quad\left(\begin{array}{cccc}1 & 7 & 3 & 2 \\ 1 / 7 & 1 & 1 / 3 & 1 \\ 1 / 3 & 3 & 1 & 2 \\ 1 / 2 & 1 & 1 / 2 & 1\end{array}\right)$

Matriz 2: Comparação par a par dos critérios à luz do objetivo do membro \#2.

\begin{tabular}{|c|c|c|c|c|}
\hline Objetivo & Café manhã & Almoço & Lanche & Jantar \\
\hline Café manhã & 1 & 5 & 3 & 5 \\
\hline Almoço & $1 / 5$ & 1 & $1 / 7$ & $1 / 3$ \\
\hline Lanche & $1 / 3$ & 7 & 1 & 2 \\
\hline Jantar & $1 / 5$ & 3 & $1 / 2$ & 1 \\
\hline
\end{tabular}

Matriz 3: Comparação par a par dos critérios à luz do objetivo do membro \#3.

\begin{tabular}{|c|c|c|c|c|}
\hline Objetivo & Café manhã & Almoço & Lanche & Jantar \\
\hline Café manhã & 1 & 3 & $1 / 7$ & $1 / 2$ \\
\hline Almoço & $1 / 3$ & 1 & $1 / 7$ & $1 / 3$ \\
\hline Lanche & 7 & 7 & 1 & 6 \\
\hline Jantar & 2 & 3 & $1 / 6$ & 1 \\
\hline
\end{tabular}

Matriz 4: Comparação par a par dos critérios à luz do objetivo do membro \#4.

\begin{tabular}{|c|c|c|c|c|}
\hline Objetivo & âfé manhã & Almoço & Lanche & Jantar \\
\hline Café manhã & 1 & 7 & $1 / 2$ & 3 \\
\hline Almoço & $1 / 7$ & 1 & $1 / 5$ & $1 / 3$ \\
\hline Lanche & 2 & 5 & 1 & 7 \\
\hline Jantar & $1 / 3$ & 3 & $1 / 7$ & 1 \\
\hline
\end{tabular}


2. Julgamentos das opções em relação ao critério café da manhã.

Matriz 5: Comparação par a par das opções à luz do critério 'café da manhã' do membro \#1.

Café manhã
B1
B2
B3 $\quad\left(\begin{array}{cccc}\text { B1 } & \text { B2 } & \text { B3 } & \text { B4 } \\ \text { B4 } & 5 & 1 / 3 & 1 / 7 \\ 1 / 5 & 1 & 1 / 7 & 1 / 9 \\ 3 & 7 & 1 & 1 / 2 \\ 7 & 9 & 2 & 1\end{array}\right)$

Matriz 6: Comparação par a par das opções à luz do critério 'café da manhã' do membro \#2.

Café manhã
B1
B2 $\quad\left(\begin{array}{cccc}1 & 1 / 5 & 1 / 7 & 1 / 9 \\ \text { B3 } & 1 & 1 / 5 & 1 / 5 \\ \text { B4 } & 5 & 1 & 2 \\ 7 & 5 & 1 / 2 & 1\end{array}\right)$

Matriz 7: Comparação par a par das opções à luz do critério 'café da manhã' do membro \#3.

\begin{tabular}{|c|c|c|c|c|}
\hline Café manhã & B1 & B2 & B3 & B4 \\
\hline B1 & 1 & 3 & $1 / 4$ & $1 / 7$ \\
\hline B2 & $1 / 3$ & 1 & $1 / 7$ & $1 / 9$ \\
\hline B3 & 4 & 7 & 1 & $1 / 5$ \\
\hline B4 & 7 & 9 & 5 & 1 \\
\hline
\end{tabular}

Matriz 8: Comparação par a par das opções à luz do critério 'café da manhã' do membro \#4.

Café manhã
B1
B2
B3 $\quad\left(\begin{array}{cccc}1 & \text { B2 } & \text { B3 } & \text { B4 } \\ \text { B4 } & 2 & 3 & 1 / 5 \\ 1 / 2 & 1 & 1 / 2 & 1 / 5 \\ 1 / 3 & 2 & 1 & 1 / 7 \\ 5 & 5 & 7 & 1\end{array}\right)$

3. Julgamentos das opções em relação ao critério almoço.

Matriz 9: Comparação par a par das opções à luz do critério 'almoço' do membro \#1.

$\left.\begin{array}{cccccc}\text { Almoço } & \mathrm{L} 1 & \mathrm{~L} 2 & \mathrm{~L} 3 & \mathrm{~L} 4 & \mathrm{~L} 5 \\ \mathrm{~L} 1 & \mathrm{1} & 3 & 1 / 7 & 1 / 3 & 1 / 5 \\ \mathrm{~L} 2 & 1 / 3 & 1 & 1 / 5 & 1 / 2 & 1 / 7 \\ \mathrm{~L} 3 & 7 & 5 & 1 & 5 & 3 \\ \mathrm{~L} 4 & 3 & 2 & 1 / 5 & 1 & 1 / 2 \\ \mathrm{~L} 5 & 5 & 7 & 1 / 3 & 2 & 1\end{array}\right)$

Matriz 10: Comparação par a par das opções à luz do critério 'almoço' do membro \#2.

$\left.\begin{array}{cccccc}\begin{array}{c}\text { Almoço } \\ \text { L1 }\end{array} & \text { L1 } & \text { L2 } & \text { L3 } & \text { L4 } & \text { L5 } \\ \text { L2 } & 1 / 5 & 5 & 1 / 3 & 1 / 5 & 1 / 7 \\ \text { L3 } & 1 & 1 / 3 & 1 / 7 & 1 / 9 \\ \text { L4 } & 3 & 3 & 1 & 1 / 3 & 1 / 5 \\ \text { L5 } & 5 & 7 & 3 & 1 & 1 / 3 \\ 7 & 9 & 5 & 3 & 1\end{array}\right)$


Matriz 11: Comparação par a par das opções à luz do critério 'almoço' do membro \#3.

$\left.\begin{array}{cccccc}\text { Almoço } & \mathrm{L} 1 & \mathrm{~L} 2 & \mathrm{~L} 3 & \mathrm{~L} 4 & \mathrm{~L} 5 \\ \mathrm{~L} 1 & 1 & 2 & 2 & 1 / 2 & 1 \\ \mathrm{~L} 2 & 1 / 2 & 1 & 2 & 1 / 2 & 1 / 2 \\ \mathrm{~L} 3 & 1 / 2 & 1 / 2 & 1 & 2 & 1 / 2 \\ \mathrm{~L} 4 & 2 & 2 & 1 / 2 & 1 & 1 / 2 \\ \mathrm{~L} 5 & 1 & 2 & 2 & 2 & 1\end{array}\right)$

Matriz 12: Comparação par a par das opções à luz do critério 'almoço' do membro \#4.

$\left.\begin{array}{cccccc}\begin{array}{c}\text { Almoço } \\ \text { L1 }\end{array} & \text { L1 } & \text { L2 } & \text { L3 } & \text { L4 } & \text { L5 } \\ \text { L2 } & 1 / 5 & 5 & 7 & 9 & 2 \\ \text { L3 } & 1 / 7 & 1 / 3 & 3 & 5 & 1 / 5 \\ \text { L4 } & 1 / 9 & 1 / 5 & 1 / 5 & 5 & 1 / 5 \\ \text { L5 } & 1 / 2 & 5 & 5 & 9 & 1 / 9\end{array}\right)$

4. Julgamentos das opções em relação ao critério lanche.

Matriz 13: Comparação par a par das opções à luz do critério 'lanche' do membro \#1.

$\left.\begin{array}{ccccc}\begin{array}{c}\text { Lanche } \\ \text { S1 } \\ \text { S2 } \\ \text { S3 }\end{array} & \text { S1 } & \text { S2 } & \text { S3 } & \text { S4 } \\ 1 & 7 & 3 & 1 / 3 \\ \text { S4 } & 1 / 7 & 1 & 1 / 5 & 1 / 7 \\ 1 / 3 & 5 & 1 & 1 / 5 \\ 3 & 7 & 5 & 1\end{array}\right)$

Matriz 14: Comparação par a par das opções à luz do critério 'lanche' do membro \#2.

\begin{tabular}{|c|c|c|c|c|}
\hline Lanche & S1 & S2 & S3 & S4 \\
\hline S1 & 1 & $1 / 3$ & $1 / 5$ & $1 / 7)$ \\
\hline S2 & 3 & 1 & $1 / 3$ & $1 / 7$ \\
\hline S3 & 5 & 3 & 1 & $1 / 5$ \\
\hline S4 & 7 & 7 & 5 & 1 \\
\hline
\end{tabular}

Matriz 15: Comparação par a par das opções à luz do critério 'lanche' do membro \#3.

\begin{tabular}{|c|c|c|c|c|}
\hline Lanche & S1 & S2 & S3 & S4 \\
\hline S1 & 1 & 3 & 7 & $1 / 4$ \\
\hline S2 & $1 / 3$ & 1 & 5 & $1 / 7$ \\
\hline S3 & $1 / 7$ & $1 / 5$ & 1 & $1 / 9$ \\
\hline S4 & 4 & 7 & 9 & 1 \\
\hline
\end{tabular}

Matriz 16: Comparação par a par das opções à luz do critério 'lanche' do membro \#4.

\begin{tabular}{|c|c|c|c|c|}
\hline Lanche & S1 & S2 & S3 & S4 \\
\hline S1 & 1 & $1 / 5$ & 5 & $1 / 7$ \\
\hline S2 & 5 & 1 & 7 & 1 \\
\hline S3 & $1 / 5$ & $1 / 7$ & 1 & $1 / 9$ \\
\hline S4 & 7 & 1 & 9 & 1 \\
\hline
\end{tabular}


5. Julgamentos das opções em relação ao critério jantar.

Matriz 17: Comparação par a par das opções à luz do critério 'jantar’ do membro \#1.

$\left.\begin{array}{cccccccc}\text { Jantar } & \mathrm{D} 1 & \mathrm{D} 2 & \mathrm{D} 3 & \mathrm{D} 4 & \mathrm{Y} 1 & \mathrm{Y} 2 & \mathrm{Y} 3 \\ \mathrm{D} 1 & 1 & 3 & 3 & 1 / 2 & 1 / 5 & 1 & 7 \\ \mathrm{D} 2 & 1 / 3 & 1 & 1 / 3 & 1 / 5 & 1 / 7 & 1 / 7 & 3 \\ \mathrm{D} 3 & 1 / 3 & 3 & 1 & 1 / 2 & 1 / 5 & 3 & 5 \\ \mathrm{D} 4 & 2 & 5 & 2 & 1 & 1 / 3 & 2 & 5 \\ \mathrm{Y} 1 & 5 & 7 & 5 & 3 & 1 & 5 & 9 \\ \mathrm{Y} 2 & 1 & 7 & 1 / 3 & 1 / 2 & 1 / 5 & 1 & 7 \\ \mathrm{Y} 3 & 1 / 7 & 1 / 3 & 1 / 5 & 1 / 5 & 1 / 9 & 1 / 7 & 1\end{array}\right)$

Matriz 18: Comparação par a par das opções à luz do critério 'jantar’ do membro \#2.

$\left.\begin{array}{cccccccc}\text { Jantar } & \text { D1 } & \text { D2 } & \text { D3 } & \text { D4 } & \text { Y1 } & \text { Y2 } & \text { Y3 } \\ \text { D1 } & 1 & 1 / 5 & 3 & 5 & 1 / 9 & 1 / 7 & 1 / 7 \\ \text { D2 } & 5 & 1 & 5 & 7 & 1 / 3 & 1 / 5 & 1 / 3 \\ \text { D3 } & 1 / 3 & 1 / 5 & 1 & 3 & 1 / 7 & 1 / 7 & 1 / 7 \\ \text { D4 } & 1 / 5 & 1 / 7 & 1 / 3 & 1 & 1 / 9 & 1 / 9 & 1 / 9 \\ \text { Y1 } & 9 & 3 & 7 & 9 & 1 & 1 / 3 & 2 \\ \text { Y2 } & 7 & 5 & 7 & 9 & 3 & 1 & 2 \\ \text { Y3 } & 7 & 3 & 7 & 9 & 1 / 2 & 1 / 2 & 1\end{array}\right)$

Matriz 19: Comparação par a par das opções à luz do critério 'jantar’ do membro \#3.

$\left.\begin{array}{cccccccc}\text { Jantar } & \mathrm{D} 1 & \mathrm{D} 2 & \mathrm{D} 3 & \mathrm{D} 4 & \mathrm{Y} 1 & \mathrm{Y} 2 & \mathrm{Y} 3 \\ \mathrm{D} 1 & 1 & 1 / 3 & 4 & 1 / 4 & 1 / 5 & 1 / 7 & 1 / 3 \\ \mathrm{D} 2 & 5 & 1 & 6 & 1 / 2 & 1 / 3 & 1 / 5 & 2 \\ \mathrm{D} 3 & 1 / 4 & 1 / 6 & 1 & 1 / 6 & 1 / 7 & 1 / 8 & 1 / 5 \\ \mathrm{D} 4 & 4 & 2 & 6 & 1 & 1 / 4 & 1 / 5 & 1 / 2 \\ \mathrm{Y} 1 & 5 & 3 & 7 & 4 & 1 & 1 / 4 & 5 \\ \mathrm{Y} 2 & 7 & 5 & 8 & 5 & 4 & 1 & 4 \\ \mathrm{Y} 3 & 3 & 1 / 2 & 5 & 2 & 1 / 5 & 1 / 4 & 1\end{array}\right)$

Matriz 20: Comparação par a par das opções à luz do critério 'jantar' do membro \#4.

\begin{tabular}{|c|c|c|c|c|c|c|c|}
\hline Jantar & D1 & D2 & D3 & D4 & Y1 & $\mathrm{Y} 2$ & $\mathrm{Y} 3$ \\
\hline D1 & 1 & $1 / 5$ & $1 / 7$ & 3 & $1 / 5$ & $1 / 2$ & $1 / 7$ \\
\hline D2 & 5 & 1 & 2 & 5 & 7 & 2 & 1 \\
\hline D3 & 7 & $1 / 2$ & 1 & 7 & 5 & 2 & $1 / 2$ \\
\hline D4 & $1 / 3$ & $1 / 5$ & $1 / 7$ & 1 & $1 / 3$ & $1 / 7$ & $1 / 9$ \\
\hline Y1 & 5 & $1 / 7$ & $1 / 5$ & 3 & 1 & $1 / 5$ & $1 / 7$ \\
\hline Y2 & 2 & $1 / 2$ & $1 / 2$ & 7 & 5 & 1 & $1 / 3$ \\
\hline Y3 & 7 & 1 & 2 & 9 & 7 & 3 & \\
\hline
\end{tabular}

